\title{
Pengaruh konsenterasi dan ukuran bank serta inflasi terhadap stabilitas bank pembangunan daerah
}

\author{
Rizky Yudaruddin \\ Fakultas Ekonomi dan Bisnis Universitas Mulawarman, Samarinda. \\ Email: aa_rizkyyudaruddin@yahoo.co.id
}

\begin{abstract}
Abstrak
Adanya wacana penggabungan Bank Pembangunan Daerah (BPD) di Indonesia akan meningkatkan konsenterasi pasar bagi BPD. Namun peningkatan konseterasi akan memiliki dua kemungkinan yaitu menciptakan stabilitas atau ketidakstabilian. Penelitian bertujuan menganalisis dampak peningkatan konsenterasi BPD terhadap stabilitas dengan variabel ukuran dan inflasi sebagai variabel kontrol. Data yang digunakan adalah data sekunder yang berupa laporan keuangan BPD mulai tahun 2003 - 2013. Alat analisis yang digunakan dalam penelitian ini adalah regresi data panel. Hasil penelitian menemukan hubungan peningkatan konsenterasi akan meningkatkan stabilitas dengan arah hubungan positif dan signifikan. Ini berarti mendukung hipotesis "concentration-stability". Variabel ukuran bank memiliki dampak negatif dan signifikan terhadap stabilitas bank BPD sedangkan untuk variabel inflasi berdampak negatif namun tidak signifikan.
\end{abstract}

Kata Kunci: Satbilitas; konsenterasi pasar; ukuran bank

\section{Impact of economic conditions and interest rate home and host country on growth credit foreign banks in indonesia}

\begin{abstract}
The research aims to study the impact of the country's economic conditions and interest rates rill home country and the host country of the loan especially in foreign bank in Indonesia. The data used are secondary data in the form of financial statements of foreign banks starting in 2003 - 2013. The analytical tool used in this research is panel data regression. The study found a relationship between economic conditions home country of the foreign bank lending in the host country and a significant negative. For the host country economic conditions, showed positive and significant relationship towards lending in the host country. As for the variable interest rate home country has a positive and significant relationship with a foreign bank lending in the host country. While the variable interest rate host country has a significant positive relationship and not with foreign bank lending in the host country.
\end{abstract}

Keywords: Economic conditions; interest rates 


\section{PENDAHULUAN}

Wacana pengabungan Bank Pembangunan Daerah (BPD) oleh Otoritas Jasa Keuangan (OJK) ditanggapi pro dan kontera berbagai pihak. Adanya kesiapan menghadapi Masyarakat Ekonomi ASEAN (MEA 2015) dinilai sebagai salah satu alasannya. Hal ini terjadi karena lemahnya daya saing BPD dibandingkan bank lain. Berdasarkan review dari Otoritas Jasa Keuangan (OJK) tahun 2014, Share BPD dibanding industri, baik dari sisi Total Aset, Kredit dan DPK masih relatif rendah $(<10 \%)$ dan relatif stagnan sepanjang 3 (tiga) tahun terakhir. Hal ini mengindikasikan masih rendahnya daya saing BPD secara relatif terhadap kinerja bank umum lainnya dalam industri.

Selain itu, Otoritas Jasa Keuangan (OJK) menilai kiprah BPD dalam industri masih sangat minim. Dari sisi aset, permodalan, serta penyaluran kredit BPD sangat tertinggal jauh dengan bank swasta dan bank milik pemerintah pusat (BUMN). Meskipun pertumbuhan aset dan dana pihak ketiga (DPK) BPD tidak bisa dianggap remeh. Hingga Desember 2014 pertumbuhan asset BPD mengalami pertumbuhan sebesar 13,01 persen (yoy) dari Rp 389,964 triliun menjadi Rp 440,691 triliun, sedikit di bawah industri yang pertumbuhannya mencapai 13,34 persen. Hal ini karena ditopang oleh pertumbuhan DPK yang naik 16,77 persen dari Rp 287,709 triliun menjadi Rp 335,957 triliun. Untuk, kuartal I 2015, total aset BPD mencapai Rp 498 triliun, total kredit Rp 304 triliun, dan total DPK Rp 410 triliun. Sementara itu, total kredit BPD sepanjang 2014 tercatat naik 13,95 persen dari Rp 264,541 triliun menjadi $\mathrm{Rp}$ 301,456 triliun, lebih tinggi dari pertumbuhan industri sebesar 11,65 persen. Sebagian besar masih berupa kredit konsumtif sebesar 68 persen.

Jika wacana pengabungan terealisasi maka dari sisi aset, BPD akan menjadi bank terbesar nomor 4 (empat) secara nasional. Meskipun kondisi ini menyebabkan terjadi perubahan pada struktur pasar pada BPD. Konsenterasi pasar bank menjadi meningkat. Peningkatan konsenterai ini dikahwatirkan akan menurunkan tingkat persaingan bank. Beberapa hasil penelitian menunjukan peningkatan konsenterasi menurunkan tingkat kompetisi dan meningkatkan profitabilitas. Chirwa (2001) menemukan dalam jangka panjang ada hubungan antara struktur pasar dengan profitabilitas perbankan Malawi. Hipotesis kolusi didukung karena adanya hubungan positif signifikan antara profitabilitas bank komersial dengan tingkat konsenterasi. Sathye (2005) menemukan kebijakan merger empat bank besar di Australia menyebabkan penurunan kompetisi sistem perbankan Australia sehinga bank tidak dapat menjadi efisien. Berger dan Hannan (1989), Naylah (2010), Bhatti dan Hussain (2010), dan Gajurel dan Pradhan (2011) menemukan bahwa peningkatan konsenterasi pasar menurunkan kompetisi dan meningkatkan profit.

Jika wacana pengabungan terjadi, apakah kondisi ini memberikan kesetabilan bagi BPD? Meskipun berdasarkan kajian menunjukan adanya hasil yang berbeda dari dampak konsenterasi terhadap stabilitas. Demirgüç-Kunt dan Levine (2003) Beck et al. (2006), Chang et al (2007) dan Uhde dan Heimeshoff (2009) menjelaskan hubungan antara tingkat konsenterasi dengan kesetabilan bank dibagi menjadi dua hipotesis yaitu pertama, hipotesis "concentration-stability" dan kedua, hipotesis "concentration-fragility". Hipotesis "concentration-stability" artinya bank yang memiliki tingkat konsenterasi yang rendah lebih mudah terkena krisis keuangan/ketidakstabilan dari pada bank besar yang terkonsentarsi. Hal sebaliknya ada pada hipotesis "concentration-fragility" yang berarti sebaliknya, bank yang terkonsentarsi lebih mudah terkenan krisis keuangan/ketidakstabilan. Meskipun hasil penelitian Ruiz-Porras (2007) dan Jiménez et al (2010) menemukan hasil bahwa tingkat konsenterasi bank tidak berpengaruh signifikan terhadap krisis keuangan/ketidakstabilan.

Melihat kondisi ini maka tujuan penelitian ini adalah untuk mengetahui pengaruh tingkat konsenterasi terhadap stabilitas bank di Indonesia. Apakah BPD di Indonesia peningkatan konsenterasi akan meningkatkan stabilitas (hipotesis "concentration-stability") atau tidak (hipotesis "concentrationfragility"). Selain itu, dilibatkan variabel ukuran bank dan inflasi sebagai variabel kontrol.

\section{Landasan Teori}

\section{Hubungan Konsenterasi dan Stabilitas Bank}

Demirgüç-Kunt dan Levine (2003), Beck et al. (2006), Chang et al. (2007), Uhde dan Heimeshoff (2009) menjelaskan hubungan antara tingkat konsentrasi dengan kesetabilan bank dibagi menjadi dua hipotesis yaitu pertama, hipotesis "concentration-stability" dan kedua, hipotesis 
"concentration-fragility". Hipotesis "concentration-stability" artinya bank yang memiliki tingkat konsentrasi yang rendah lebih mudah terkena krisis keuangan/ketidakstabilan dari pada bank besar yang terkonsentarsi. Hal sebaliknya ada pada hipotesis "concentration-fragility" yang berarti sebaliknya, bank yang terkonsentarsi lebih mudah terkenan krisis keuangan/ketidakstabilan. Meskipun hasil penelitian Ruiz-Porras (2007) dan Jiménez et al (2010) menemukan hasil bahwa tingkat konsentrasi bank tidak berpengaruh signifikan terhadap krisis keuangan/ketidakstabilan.

Northcott (2004) menjelaskan tujuan dari regulasi perbankan adalah menghasilkan ekonomi yang efisien dan stabil. Namun tidak ada kajian literature yang menunjukan struktur persaingan yang dapat mengoptimalkan efisiensi dan stabilitas. Jadi terjadilah trede off antara efisiensi dan stabilitas. Misalnya, hasil penelitian Fernández and Garza-Garcíab (2012) yang mendukung hubungan yang positif antara persaingan bank besar dengan kesetabilan bank atau mendukung "competition-stability". Meskipun ditemukan pula hubungan yang negatif antara persaingan bank yang memiliki portofolio resiko yang besar sehingga mendukung "competition-fragility". Sedangkan Tabak et al (2011) menemukan pada bank besar mendukung "competition-stability".

Berbagai hasil penelitian yang dilakukan berbagai peneliti memang menunjukan adanya hasil yang mendukung kedua hipotesis tersebut. Fernández and Garza-Garcíab (2012), Tabak et al (2011), Koopman (2011), Deltuvaite (2010), Schaeck et al (2009), Evrensel (2008), Chang et al (2007), Schaeck dan Čihák (2007), Yeyati dan Micco (2007), Beck et al (2006), Boyd et al (2006) dan Allen dan Douglas (2003), mendukung "competition-stability". Sedangkan hasil penelitian Beck et al (2012), Uhde dan Heimeshoff (2009), Schaeck, et al (2009), Berger et al (2008) Ruiz-Porras (2007) dan De Nicoló et al (2003) mendukung "competition-fragility".

\section{Hubungan Ukuran dan Stabilitas Bank}

Aset merupakan aktiva yang digunakan untuk aktivitas operasional perusahaan. Tottal Asset ialah segala sumber daya yang dikuasai oleh perusahaan sebagai akibat dari transaksi masa lalu dan diharapkan akan memberikan manfaat ekonomi bagi perusahaan di masa yang akan datang. Semakin besar aset yang dimiliki maka diharapkan akan semakin besar hasil operasional perusahaan. Peningkatan aset yang diikuti dengan peningkatan hasil operasi akan semakin meningkatkan kepercayaan dari pihak eksternal terhadap perusahaan. Berdasarkan teori skala efisiensi dapat disimpulkan bahwa perusahaan dengan aset yang besar mampu menghasilkan keuntungan lebih besar apabila diikuti dengan hasil dari aktivitas operasionalnya. Namun kondisi tersebut dapat berbalik apabila pihak manajemen bank tidak mampu mengelola asetnya dengan efisien sehingga memungkinkan timbulnya risiko yang akan semakin bertambah sejalan dengan peningkatan aset.

Peningkatan ukuran bank dapat berdampak positif dan negatif bagi bank. Berdampak positif, jika peningkatan ukuran bank menciptakan scala ekonomi bagi bank sehingga bank menjadi lebih efisien dan stabil. Sebaliknya, jika peningkatan ukuran bank menyebabkan bank menjadi tidak fleksibel dalam operasional. Hasil penelitian Fernández and Garza-Garcíab (2012), Tabak et al (2011), Yeyati dan Micco (2007), dan Boyd et al (2006) menemukan bahwa peningkatan total asset bank akan berdampak negatif signifikan bagi stabilitas bank. Hal berbeda ditemukan oleh Beck et al (2012), dan Schaeck et al (2009), yang menemukan bahwa peningkatan total asset bank akan berdampak positif signifikan bagi stabilitas bank.

\section{Hubungan Inflasi dan Stabilitas Bank}

Inflasi merupakan salah satu indikator ekonomi yang harus dipertimbangkan dalam proses investasi. Inflasi yang tinggi menyebabkan suku bunga perbankan yang tinggi, sehingga dapat meningkatkan besarnya kredit bermasalah dan lemahnya kondisi internal bank. Meningkatnya inflasi maka nilai uang akan "menurun" dan hal tersebut menyebabkan masyarakat juga merasa tidak diuntungkan dengan menyimpan uang di bank dengan harapan bunga ditengah inflasi yang tinggi, sehingga mereka enggan untuk menabung,yang menyebabkan dana yang dihimpun bank akan menjadi lebih kecil.

Peningkatan inflasi dapat berdampak bagi stabilitas bank jika tidak diikuti dengan peningkatan suku bunga. Namun antisipasi peningkatan suku bunga juga akan berdampak semakin meningkatnya biaya bunga bagi debitor. Hasil penelitian Deltuvaite (2010), Chang et al (2007), dan De Nicoló et al 
(2003) menunjukan hasil negatif namun tidak signifikan. Sedangkan penelitian Uhde dan Heimeshoff (2009), adanya pengaruh negatif signifikan antara inflasi terhadap stabilitas.

\section{METODE}

Model dalam penelitian ini mengadaptasi penelitian Deltuvaitė (2010), Yeyati dan Micco (2007), dan Uhde dan Heimeshoff (2009), yang secara operasional terdapa pada tabel I dengan model sebagai berikut:

$$
\text { Z-score } \text { it i,t }=\alpha+\beta_{1} \text { Cons }_{i, t}+\beta_{2} \operatorname{Size}_{i, t}+\beta_{3} \operatorname{Inf}_{i, t}+\varepsilon_{i, t}
$$

Tabel 1. Definisi Operasional Variabel Penelitian

\begin{tabular}{|c|c|c|c|}
\hline \multicolumn{2}{|c|}{ Variabel } & Deskripsi & Sumber Data \\
\hline Z-score & Stabilitas & $\begin{array}{l}\text { Z-score }_{\text {it }}=\frac{R O A_{i t}+(E / A)_{i t}}{\partial(R O A)_{i t}} \\
\text { Jumlah Return on Asset (ROA) ditambah rasio } \\
\text { modal (E) dengan Total Asset (A) dibagi standar } \\
\text { deviasi ROA bank i pada tahun t }\end{array}$ & Bank Indonesia \\
\hline Cons & Konsenterasi & $\begin{array}{l}\text { Indeks Hirschman-Herfindahl (HHI) bank i pada } \\
\text { tahun t yang dihitung dengan rumus: } \\
\mathrm{HHI}=\sum_{i=1}^{\mathrm{N}} \mathrm{MSi}^{2} \text { dimana MS = Market Share } \\
\text { Market Share atau Pangsa Pasar bank i pada } \\
\text { tahun t yang dihitung dengan rumus: } \\
\mathrm{MS}_{\mathrm{DPK}}=\frac{\text { Total DPK bank } i}{\text { Total DPK seluruh bank }} \times 100 \% \\
\text { DPK = Dana Pihak Ketiga }\end{array}$ & Bank Indonesia \\
\hline Size & Ukuran Bank & Lognatura Total Asset Bank i pada tahun t & Bank Indonesia \\
\hline Inf & Inflasi & $\begin{array}{l}\text { Tingkat suku bunga rill home country adalah } \\
\text { suku bunga kredit dikurangi dengan inflasi di } \\
\text { home country }\end{array}$ & $\begin{array}{l}\text { TheGlobaleconom } \\
\text { y }\end{array}$ \\
\hline$\beta_{1}-\beta_{3}$ & Koefisien reg & & \\
\hline$\varepsilon_{\text {it }}$ & Nilai residua & & \\
\hline
\end{tabular}

Data yang digunakan adalah data sekunder yang berupa laporan keuangan Bank Pembangunan Daerah se-Indonesia mulai tahun 2003 - 2013, yang dipublikasikan pada website Bank Indonesia (www.bi.go.id). Ada 26 bank BPD yang dianalisis. Alat analisis yang digunakan dalam penelitian ini adalah regresi data panel. Pemilihan model regresi data panel dilakukan pengujian yaitu uji chow dan uji hausman sehingga dapat diketahui model regresi yang tepat yaitu model PLS, Fixed Effect atau Random Effect (Juanda dan Junaidi, 2012). Dalam menentukan mana yang terbaik antara model Pooled OLS Method (PLS) dengan Metode Fixed Effect (FEM) dilakukan dengan cara uji Chow. Jika berdasarkah hasil output uji chow nilai $\mathrm{F}$ test maupun nilai chi-square signifikan maka metode FEM lebih baik dibandingkan dengan metode PLS, jika tidak signifikan maka metode PLS lebih baik. Setelah didapat hasil bahwa metode Fixed Effect lebih baik dibandingkan Polled OLS Method, maka langkah selanjutnya yaitu menguji untuk membandingkan antara metode Fixed Effect dengan Random Effect. Uji yang dilakukan untuk menguji hal tersebut adalah dengan Hausman Test. Jika hasilnya signifikan maka FEM lebih baik dari Random Effect Method (REM). Untuk uji asumsi klasik akan digunakan uni multikolineritas, heterokedatasitas dan autokolerasi (Gujarati, 2010).

\section{HASIL DAN PEMBAHASAN}

Pada estimasi dampak peningkatan konsenterasi, ukuran bank dan inflasi terhadap stabilitas bank BPD di Indonesia tahun 2004-2013 menggunakan regresi data panel. Hasil analisis untuk mengetahui model yang terbaik dilakukan dengan pengujian yaitu uji chow dan uji hausman sehingga 
dapat diketahui model regresi yang tepat yaitu model PLS, Fixed Effect atau Random Effect. Berdasarkan hasil uji Chow dan Uji Hausmant ditemukan hasil sebagai berikut:

Tabel 2. Hasil Uji Metode Dengan Menggunakan Uji Chow

\begin{tabular}{c|r|r|r}
\hline Effects Test & \multicolumn{1}{|c|}{ Statistic } & \multicolumn{1}{c|}{ d.f. } & \multicolumn{1}{c}{ Prob. } \\
\hline Cross-section F & 45.617575 & $(25,230)$ & 0.0000 \\
Cross-section Chi-square & 462.265108 & 25 & 0.0000 \\
\hline
\end{tabular}

Sumber: Hasil Pengolahan E-Views, 2015

Berdasarkah hasil output uji chow dari alat bantu Eviews dapat dilihat bahwa nilai $\mathrm{F}$ test maupun nilai chi-square signifikan yaitu sebesar 0,0000 lebih kecil dari 0,05. Ini berarti bahwa hipotesis null ditolak, sehingga metode FEM lebih baik dibandingkan dengan metode PLS. Setelah didapat hasil bahwa metode Fixed Effect lebih baik dibandingkan Polled OLS Method, maka langkah selanjutnya yaitu menguji untuk membandingkan antara metode FEM dengan REM. Uji yang dilakukan untuk menguji hal tersebut adalah dengan Hausman Test.

Tabel 3. Hasil Uji Metode Dengan Menggunakan Hausman Test

\begin{tabular}{c|c|c|c}
\hline Test Summary & Chi-Sq. Statistic & Chi-Sq. d.f. & Prob. \\
\hline Cross-section random & 2.895463 & 3 & 0.4080 \\
\hline
\end{tabular}

Sumber: Hasil Pengolahan E-Views, 2015

Berdasarkan hasil output uji Hausman dengan alat bantu Eviews versi 6, terlihat bahwa nilai p-value lebih besar dari 0,05 yaitu sebesar 1,000. Dengan demikian dapat disimpulkan bahwa REM lebih baik dibandingkan FEM. Hasil analisis juga menunjukan bahwa tidak terjadi multikolinearitas, autokolerasi dan heterekodaktasitas dengan hasil REM sebagai berikut:

Tabel 4. Hasil Analisis Regresi Data Panel

\begin{tabular}{l|c|c|c|c|c|c}
\hline $\begin{array}{c}\text { Variabel } \\
\text { terikat }\end{array}$ & $\begin{array}{c}\text { Variabel } \\
\text { bebas }\end{array}$ & $\begin{array}{c}\text { Koefisien } \\
\text { Regresi }\end{array}$ & t statistik & Prob. & Arah & Ket. \\
\hline \multirow{4}{*}{ Z-score } & Konstanta & 5.602623 & 2.686564 & 0.0077 & $(+)$ & Sig. \\
& Cons & 0.006423 & 4.880237 & 0.0000 & $(+)$ & Sig. \\
& Size & -0.354234 & -2.807746 & 0.0054 & $(-)$ & Sig. \\
& Inf & -0.002042 & -0.643469 & 0.5205 & $(-)$ & Tidak Sig. \\
\hline R -Square & $: 0.147376$ & & & \\
Adjust R -Square & $: 0.137345$ & & & \\
F -Statistik & $: 14.69224$ \\
F Signifikan & $: 0.000000$
\end{tabular}

Hasil analisis regresi data panel pada tabel IV menujukan bahwa nilai R-Square sebesar 0,147 yang berarti bahwa 14,7\% variansi variabel dependen dapat dijelaskan oleh variabel independen, sedangkan sisanya sebesar $85,3 \%$ dijelaskan oleh variabel lain yang tidak terdapat dalam model penelitian ini. F statistik sebesar 14.6922 dengan nilai probabilitas (F signifikan) sebesar 0,0000 yang lebih kecil dari 0,05 menjelaskan bahwa model regresi tersebut dapat digunakan untuk memprediksi stabilitas bank BPD yang berarti model yang layak atau yang baik. Hasil analisis menujukan model memenuhi asumsi klasik yaitu normalitas, autokorelasi, heterokedaktasitas dan multikolineartias.

Hasil penelitian menemukan bahwa peningkatan konsenterasi akan meningkatkan stabilitas dengan arah hubungan positif dan signifikan. Ini berarti mendukung hipotesis "concentration-stability" artinya bank yang memiliki tingkat konsentrasi yang rendah lebih mudah terkena krisis keuangan/ketidakstabilan dari pada bank besar yang terkonsentarsi. Hasil ini mendukung penelitian sebelumnya Fernández and Garza-Garcíab (2012), Tabak et al (2011), Koopman (2011), Deltuvaitė (2010), Schaeck et al (2009), Evrensel (2008), Chang et al (2007), Schaeck dan Čihák (2007), Yeyati 
dan Micco (2007), Beck et al (2006), Boyd et al (2006) dan Allen dan Douglas (2003). Jadi adanya wacana pengabungan bank BPD yang akan berdampak bagi peningkatan konsenterasi bank BPD akan memberikan kesetabilan bagi bank.

Variabel ukuran bank memiliki dampak negatif dan signifikan terhadap stabilitas bank BPD. Peningkatan ukuran bank yang diproxikan dari total asset yang dimiliki bank memiliki dampak yang ambigu. Peningkatan ukuran dapat memberi pengaruh positif dan negatif bagi stabilitas bank. Adanya pengaruh negatif dan signifikan menandakan bahwa peningkatan ukuran pada bank BPD akan menurunkan stabilitas bagi bank BPD. Artinya peningkatan ukuran bank BPD membuat bank BPD menjadi tidak fleksibel dalam operasionalnya. Hasil ini sesuai dengan penelitian Fernández and GarzaGarcíab (2012), Tabak et al (2011), Yeyati dan Micco (2007), dan Boyd et al (2006) menemukan bahwa peningkatan total asset bank akan berdampak negatif signifikan bagi stabilitas bank.

Untuk variabel inflasi berdampak negatif namun tidak signifikan. Adanya pengaruh negatif menandakan bahwa peningkatan inflasi dapat menurunkan stabilitas bank. Meningkatnya inflasi maka nilai uang akan "menurun" dan hal tersebut menyebabkan masyarakat juga merasa tidak diuntungkan dengan menyimpan uang di bank dengan harapan bunga ditengah inflasi yang tinggi, sehingga mereka enggan untuk menabung,yang menyebabkan dana yang dihimpun bank akan menjadi lebih kecil dan menggangu fungsi intermediasi bank. Hasil ini mendukung penelitian penelitian Deltuvaite (2010), Chang et al (2007), dan De Nicoló et al (2003) menunjukan hasil negatif namun tidak signifikan.

\section{SIMPULAN}

Berdasarkan dampak peningkatan konsenterasi, ukuran bank dan inflasi terhadap stabilitas bank BPD di Indonesia tahun 2004-2013 menggunakan regresi data panel maka dapat disimpulkan sebagai berikut:

1. Peningkatan konsenterasi akan meningkatkan stabilitas dengan arah hubungan positif dan signifikan. Ini berarti mendukung hipotesis "concentration-stability".

2. Variabel ukuran bank memiliki dampak negatif dan signifikan terhadap stabilitas bank BPD sedangkan untuk variabel inflasi berdampak negatif namun tidak signifikan.

3. Untuk penelitian selanjutnya, perlu dilihat lebih rinci tentang dampak peningkatan kosenterasi bagi bank asing dan bank domestik.

\section{DAFTAR PUSTAKA}

Allen, Franklin and Gale, Douglas. (2003) Competition and Financial Stability. Journal of Money, Credit, and Banking, 36:3; 453-480.

Beck, Thorsten. De Jonghe, Olivier. And Schepens, Glenn. (2012). Bank Competition and Stability: Cross-Country Heterogeneity. European Banking Center Discussion Paper No. 2012-026

Beck, Thorsten. Demirgüç-Kunt. Asli and Levine. Ross (2006). Bank Concentration, Competition, and Crises: First Results. Jurnal of Banking and Finance: 30; 1581-1603.

Berger, Allan N. and T. Hannan. (1989) The Price-Concentration Relationship in Banking. Review of Economics \& Statistics, 71: 2. pp. 291-99

Berger, Allen N. Klapper. Leora F.; Turk-Ariss, Rima. (2008) Bank Competition and Financial Stability.The World Bank. Policy Research Working Paper 4696.

Bhatti, Ghulam Ali and Hussain,. Haroon. (2010) Evidence on Structure Conduct Performance Hypothesis in Pakistani Commercial Banks. International Journal of Business and Management Vol. 5, No. 9; September 2010.

Boyd, John. Nicoló, Gianni de. and Jalal, Abu M. (2006). Bank Risk Taking and Competition Revisited: New Theory and New Evidence. IMF Working Paper 06/297 (Washington: International Monetary Fund). 
Chang, E.J., Guerra, S.M., Lima, E.J.A., Tabak, B. M.. (2007). The Stability-Concentration Relationship in the Brazilian Banking System. Working Paper Series 145. The Banco Central do Brasil.

Chirwa, Ephraim W. T.. (2001) Market Structure, Liberalization And Performance In The Malawian Banking Industri”. AERC Research Paper 108. African Economic Research Consortium. Nairobi.

De Nicoló, G., Bartholomew, P., Zaman, J., and Zephirin, M. (2003). Bank Consolidation, Internationalization, and Conglomeration: Trends and Implications for Financial Risk. Financial Markets, Institutions \& Instruments. IMF Working Paper 03/158 (Washington: International Monetary Fund).

Deltuvaite, Vilma. (2010) The Concentration-Stability Relationship in The Banking System: An Empirical Research. Ekonomika IR Vadyba; pp 900-909

Demirgiiu-Kunt, Asli. Laeven, Luc. and Levine, Ross. (2003). The Impact of Bank Regulations, Concentration, and Institutions on Bank Margins. The Word Bank. Policy Research Working Paper 3030.

Evrensel, A.Y. (2008) Banking Crisis and Financial Structure: A Survival-Time Analysis. International Review of Economics \& Finance, Vol. 17 (4), 589-602.

Fernández, Raúl Osvaldo and Garza-Garcíab. Jesús G. (2012) The Relationship between Bank Competition and Financial Stability: A Case Study of the Mexican Banking Industry. Centre for Global Finance. University of the West of England. Bristol.Working Paper Series (ISSN 20411596). Paper Number: 03/12.

Gajurel, Dinesh Prasad and Pradhan, Radhe Shyam. (2011) Structure-Performance Relation in Nepalese Banking Industri”. IPEDR vol.2. IAC S IT Press, Manila, Philippine. p. 25-31

Gujarati, Damodar N. Gujarati dan Porter, Dawn C. (2010). Dasar-Dasar Ekonometrika. Edisi 5. Terjemahan. Jakarta: Salemba Empat.

Jiménez, Gabriel. Lopez, Jose A. and Saurina, Jesús. (2010) How Does Competition Impact Bank Risk-Taking? Banco De Espana. Documentos de Trabajo No: 1005.

Juanda., Bambang dan Junaidi. (2012) Ekonometrika Deret Waktu; Teori dan Aplikasi. IPB Press. Bogor.

Koopman, Gert-Jan. (2011) Stability and Competition In Eu Banking During The Financial Crisis: The Role Of State Aid Control. Competition Policy International, Inc.

Naylah, Maal. (2010) Pengaruh Struktur Pasar Terhadap Kinerja Industri Perbankan Indonesia". Universitas Dipenogoro. Tesis Tidak Dipublikasikan

Northcott, Carol Ann. (2004). Competition in Banking: A Review of the Literature. Bank of Canada.Working Paper 2004-24.

Ruiz-Porras, A. (2007). Banking Competition and Financial Fragility: Evidence from Panel-Data. MPRA Paper No.5673.

Sathye, M.. (2005) Market Structure and Performance in Australian Banking”, Review of Accounting and Finance, Vol. 4, No 2, pp.107-122.

Schaeck, K., and Čihák, M. (2007). Banking Competition and Capital Ratios. Working Paper No. 07/216, International Monetary Fund.

Schaeck, K., Cihak, M., and Wolfe, S. (2009). Are Competitive Banking Systems More Stable? Journal of Money, Credit \& Banking, Vol. 41 (4), 711-734. 
Tabak, Benjamin M. Fazio, Dimas M. and Cajueiro, Daniel O. (2011). The Relationship Between Banking Market Competition And Risk-Taking: Do Size And Capitalization Matter? Working Paper Series 261. The Banco Central do Brasil.

Uhde, A., and Heimeshoff, U. (2009). Consolidation in Banking and Financial Stability in Europe: Empirical Evidence. Journal of Banking \& Finance, Vol. 33 (7), 1299-1311.

Yeyati, E.L., and Micco, A. (2007). Concentration and Foreign Penetration in Latin American Banking Sectors: Impact on Competition and Risk. Journal of Banking \& Finance, Vol. 31(6), 1633-1647. 